\title{
SITUAČ̃̃ES GERADORAS DE ANSIEDADE E ESTRATÉGIAS PARA SEU CONTROLE ENTRE ENFERMEIRAS: ESTUDO PRELIMINAR
}

\author{
Alba Lucia Botura Leite de Barros ${ }^{1}$ \\ Dorisdaia Carvalho de Humerez ${ }^{2}$ \\ Flávio Trevisani Fakih ${ }^{3}$ \\ Jeanne Liliane Marlene Michel ${ }^{4}$
}

Barros ALBL, Humerez DC, Fakih FT, Michel JLM. Situações geradoras de ansiedade e estratégias para seu controle entre enfermeiras: estudo preliminar. Rev Latino-am Enfermagem 2003 setembro-outubro; 11(5):585-92.

Este estudo teve como objetivos: identificar situações que são consideradas fontes geradoras de ansiedade, na atuação cotidiana das enfermeiras, e identificar estratégias conscientes utilizadas pelas mesmas para diminuir os níveis de ansiedade. A amostra foi constituída de 54 enfermeiras de um hospital geral de ensino, de grande porte, que responderam a um questionário contendo perguntas abertas e fechadas. As respostas apontaram situações geradoras de ansiedade, inesperadas ou cotidianas, nas áreas: assistencial, de gerenciamento e de ensino. Foram também apontados os mecanismos utilizados pelas enfermeiras para enfrentar a ansiedade, tanto nos momentos de crise como no seu cotidiano. Os resultados demonstram que, embora as profissionais estejam realmente sujeitas a situações ansiogênicas, elas também se utilizam de estratégias de enfrentamento adequadas. Verifica-se a necessidade de realização de outros estudos sobre o assunto, a fim de se proporem novas alternativas que possam melhorar a qualidade de vida das enfermeiras.

DESCRITORES: enfermagem; ansiedade; estratégias

\section{ANXIETY GENERATING SITUATIONS AMONG NURSES AND STRATEGIES TO CONTROL IT: PRELIMINARY STUDY}

The purposes of this study were: to identify situations that are considered sources of anxiety in nurse's daily activities and to identify the conscious strategies these nurses use in order to lower the level of anxiety. The sample was composed of 54 nurses from a larger general teaching hospital that answered a questionnaire with open and closed questions. The answers pointed situations, both quotidian and unsuspected, that generate anxiety in the following areas: direct care, management and teaching. Nurses also pointed the activities they usually do in order to cope with stress, during the crisis or in their quotidian life. Findings demonstrate that even though the nurses are exposed to stressing situations that generate anxiety, they also use adequate coping strategies. We observe that more studies are needed, in order to propose new alternatives to improve nurses' quality of life.

DESCRIPTORS: nursing; anxiety; strategies

\section{SITUACIONES CAUSANTES DE ANSIEDAD Y ESTRATEGIAS PARA SU CONTROL ENTRE ENFERMERAS: ESTUDIO PRELIMINAR}

Los objetivos de este estudio fueron: identificar las situaciones consideradas fuentes de ansiedad en las actividades diarias de las enfermeras e identificar las estrategias conscientes que estas enfermeras utilizan para disminuir los niveles de ansiedad. La muestra estuvo constituida por 54 enfermeras de un hospital universitario de gran porte, que respondieron a un cuestionario de preguntas abiertas y cerradas. Las respuestas mostraron situaciones generadoras de ansiedad, inesperadas o cotidianas, en las áreas de: atención directa, administración y enseñanza. También se determinaron los mecanismos utilizados por las enfermeras para enfrentar la ansiedad, tanto en los momentos de crisis como en su cotidiano. Los resultados demostraron que a pesar de encontrarse estas profesionales realmente sujetas a situaciones generadoras de ansiedad, ellas también utilizan estrategias de enfrentamiento adecuadas. Se evidencia la necesidad de realización de otros estudios sobre este tema, buscando la propuesta de nuevas alternativas para mejorar la calidad de vida de las enfermeras.

DESCRIPTORES: enfermería; ansiedad; estrategias

\footnotetext{
${ }^{1}$ Professor Livre Docente, Diretora de Enfermagem do Hospital São Paulo, e-mail: barrosalba@dhsp.epm.br; ${ }^{2}$ Professor Adjunto; ${ }^{3}$ Enfermeiro Especialista, Assessor da Diretoria de Enfermagem do Hospital São Paulo; ${ }^{4}$ Professor Assistente, Coordenadora Técnico-Administrativa da Diretoria de Enfermagem do Hospital São Paulo. Universidade Federal de São Paulo
} 
INTRODUÇÃO

$\boldsymbol{O}$ afeto é parte essencial da atividade humana, seja na forma de o ser humano comportar-se no trabalho, no lazer ou mesmo ao compartilhar com os outros. A afetividade é a base da atividade psíquica. É a parte do psiquismo de maior abrangência do domínio da atividade pessoal, sendo fundamental na conduta e reações individuais. Seu domínio vai desde a sensibilidade corporal ou física, interna e externa às sensações corpóreas dos órgãos internos, sensibilidade tátil, interpretação subjetiva das vivências conscientes ou inconscientes, dependendo de características pessoais de humor e temperamento ${ }^{(1)}$.

Ao penetrar tantos aspectos da vida psíquica, a afetividade influencia e é influenciada pela percepção, memória, pensamento, vontade e inteligência. As vivências ansiosas ou estressantes fazem parte da afetividade.

Várias vertentes científicas apontam que efeitos nocivos sobre o corpo, vinculados ao trabalho, passam, em primeiro lugar, pelo aparelho psíquico, pois é este que expressa o sofrimento e a insatisfação.

Estudos realizados encontraram correlação entre as condições organizacionais e ambientais de trabalho e os níveis de ansiedade ${ }^{(2)}$.

O termo ansiedade provém do grego Anshein, que significa oprimir, sufocar. Angústia ou ansiedade são termos correlatos, que exprimem a experiência subjetiva e são sempre associadas a manifestações de sintomas corporais.

A ansiedade acompanha a maior parte das pessoas no processo existencial. Ao sentirem algum sofrimento físico e/ou mental, que exija mudança na vida cotidiana, é esperada uma elevação de seus níveis. A ansiedade é provocada por um aumento inesperado ou previsto de tensão ou desprazer. Pode desenvolver-se em qualquer situação, seja real ou imaginária, quando a ameaça é grande para ser ignorada, dominada ou descarregada ${ }^{(3)}$.

Vários estudos demonstram que trabalhadores da área da saúde tendem a apresentar níveis altos de ansiedade, seja pelo contato com o sofrimento humano, com o processo da morte do paciente, seja pela divisão técnica ou social do trabalho, como nas relações hierarquizadas, pelas grandes jornadas e por ser, no caso da enfermagem, trabalho predominantemente feminino, considerando-se o trabalho relacionado ao gênero, o que determina uma sobrecarga por ser a mulher ainda responsável pelas tarefas domésticas ${ }^{(4-8)}$. Dessa forma, é provável que a enfermeira vivencie, em seu trabalho, situações ansiogênicas. Utilizaremos o termo enfermeira independente do gênero, apenas por representar um grupo de profissionais predominantemente feminino.

A ansiedade é expressa organicamente por sensação de mal-estar psíquico, traduzido por perturbações somáticas como as cardio-respiratórias, opressão e a sensação de ter "nós no estômago e na garganta”, além de um estado geral de hipercontração muscular. Diante da presença da ansiedade, há uma sensação de impotência e ineficácia face ao problema que se apresenta, e a tensão vai aumentando em decorrência do impacto do estímulo, o que aciona as habituais respostas homeostáticas para a solução dos problemas. A pessoa tentará diminuí-la, entretanto a falta de êxito e a continuação do estímulo estão associadas à elevação da tensão, e um novo fracasso elevará mais ainda a ansiedade. Nesse momento, atua como poderoso estímulo na mobilização de recursos internos, buscando alternativas de solução. Poderá redefinir o problema, falseando a realidade vivenciada, para que este fique no âmbito de alguma experiência anterior; pode, ainda, pôr de lado aspectos do problema que não consegue manipular, e é possível também que se resigne ou renuncie a certas metas. Assim, irá explorando os possíveis caminhos alternativos, utilizados anteriormente em outras situações ansiogênicas. De qualquer forma, a pessoa tende a redefinir o problema, pela renúncia a projetos ou pela distorção perceptual e, nesse caso, a tensão poderá ser diminuída a um limiar suportável ${ }^{(9)}$.

Segundo o mesmo autor, há dois modos para diminuir o nível de ansiedade: um deles é lidar diretamente com a situação, resolvendo o problema e tentando superar os obstáculos, e o outro é fugir das ameaças e criar estratégias, como defesas reais ou imaginárias que possam minimizar seu impacto. Dessa forma, estaremos, também, lutando para proteção da personalidade, por meio do uso dos mecanismos de defesa.

Diante do exposto, temos a intenção de desenvolver estudos para reconhecer o desconforto emocional de enfermeiras, no intuito de ajudá-las a desenvolver enfrentamentos mais apropriados, que tragam um desenvolvimento mais saudável ao cotidiano do trabalho.

Este estudo é um projeto preliminar de abordagem quantitativa, para delimitar o problema dos níveis de ansiedade nesse grupo profissional, e temos por objetivo 
identificar situações, na atuação cotidiana das enfermeiras, que são consideradas como fonte geradora de ansiedade e as estratégias conscientes que estão usando para diminuir os níveis de ansiedade.

\section{MÉTODOS}

Local e amostra

A pesquisa foi desenvolvida no Hospital São Paulo, da Universidade Federal de São Paulo, no município de São Paulo, no ano de 1999, ocasião em que foi entregue um questionário a um grupo de 240 enfermeiras, às quais foi explicado o objetivo do trabalho.

Essas 240 enfermeiras atuam tanto na assistência ao paciente quanto na administração de unidades de internação dessa instituição, em todos os turnos de trabalho, ou seja, manhã, tarde e noite.

Desse total de 240 enfermeiras, 54 devolveram o questionário respondido e foram os sujeitos deste estudo.

Técnica de coleta de dados

Para avaliar o instrumento de coleta de dados questionário, foi realizado um pré-teste com a participação de cinco enfermeiras que não participaram da pesquisa.

Após o questionário ter sido testado, passamos à coleta de dados com os sujeitos. Os dados foram coletados por meio de um questionário, contendo perguntas abertas e fechadas, com itens que a literatura relaciona como motivo de aumento do nível de ansiedade e os exemplos de estratégias utilizadas para minimizar seu impacto. Após aceitarem participar da pesquisa, os sujeitos receberam instrução para responderem ao questionário, tendo sido explicado que não seria necessária a identificação.

Os dados foram agrupados em categorias de respostas e apresentados em números absolutos e percentuais, sendo que o sujeito poderia escolher mais de uma alternativa.

\section{RESULTADOS}

Caracterização da população

Por meio dos dados, pode-se verificar o perfil dos sujeitos deste estudo: $96,29 \%$ são do sexo feminino; a faixa etária predominante está entre os 25 a 35 anos; buscam formação complementar por meio de cursos de pós-graduação; as recém-formadas representam a maioria; trabalham, em média, há 3 anos na unidade atual, sendo que $35,8 \%$ têm menos de um ano de trabalho no setor, e o turno da manhã e noturno absorvem a maior parte das respondentes.

Das 54 enfermeiras que responderam ao questionário, 20 (37,04\%) fizeram apenas graduação, e as $34(63,96 \%)$ restantes estão vinculadas, concluíram ou ainda estão cursando programas de pós-graduação.

Quando questionadas sobre estarem vinculados a outros empregos, 16 (29,6\%) responderam afirmativamente. Com relação ao tempo de formação, a média aritmética é de 6 anos, sendo que o maior percentual de enfermeiras $(39,2 \%)$ tem entre 1 e 3 anos.

Situações geradoras de ansiedade

Nos questionários respondidos, cada enfermeira indicou, subjetivamente, as situações que provocam ansiedade, sendo que, no questionário, essas situações estavam classificadas em inesperadas ou cotidianas e subdivididas, segundo a atuação, em três áreas: assistencial, gerenciamento e de ensino.

Para cada classe de situação e para cada área de atuação, apresentamos o conjunto de situações citadas entre as enfermeiras respondentes.

Situações inesperadas geradoras de ansiedade

É conhecido que situações inesperadas, novas ou desconhecidas, podem ser geradoras de ansiedade, pois nem sempre o indivíduo dispõe de suprimentos que o ajudem a atuar sem aumento de tensão. Assim, é previsível que a ansiedade esteja presente nesses momentos ${ }^{(10)}$.

Ao serem questionadas quanto à autopercepção da ansiedade, em situações inesperadas, as enfermeiras apontaram que situações específicas provocam o aumento da ansiedade.

Situações inesperadas geradoras de ansiedade, relacionadas à assistência de enfermagem ao paciente

A Figura 1 mostra os tópicos que as enfermeiras listaram como situações inesperadas, na assistência de enfermagem aos pacientes, que são percebidos por elas como geradoras de ansiedade, e o número de respostas. 


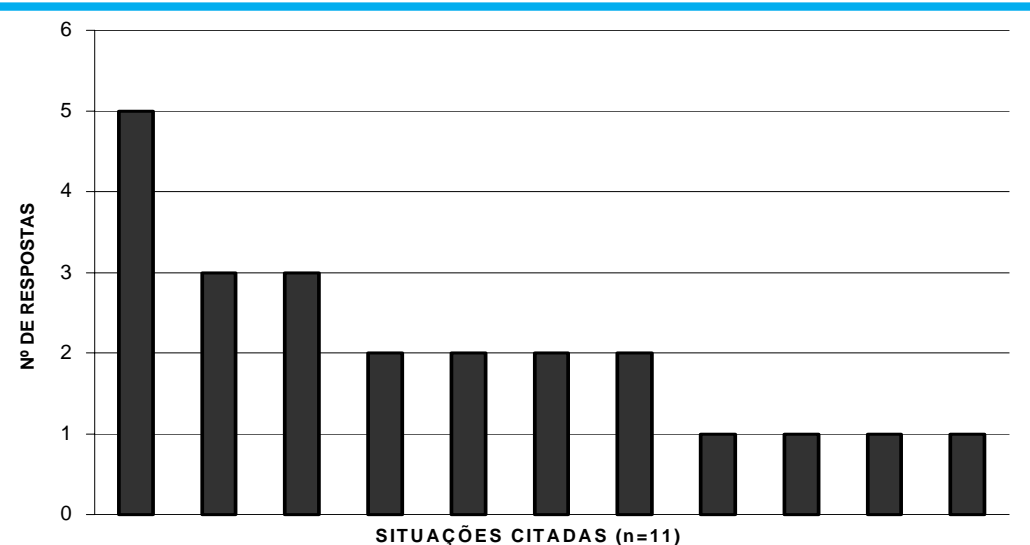

SITUAÇÕES CITADAS $(n=11)$

Instabil./ Agrav.do Estado de Saúde
$\square$ Competência Profissional do Médico
$\square$ Acidentes e Erros na Assistência
$\square$ Procedimentos de Alta Complexidade
$\square$ Óbito
$\square$ Demora no Atendimento Médico
$\square$ Queixas e Reclamações
$\square$ Admissão / Recepção de Pacientes
$\square$ Diagnósticos Indefinidos
$\square$ Cooperação Médica
$\square$ Falta de Energia Elétrica

Figura 1 - Situações inesperadas $(n=11)$ que levam à ansiedade, relacionadas à assistência de enfermagem, citadas entre 54 enfermeiras do Hospital São Paulo. São Paulo, 1999

Situações inesperadas geradoras de ansiedade, relacionadas ao gerenciamento da unidade

Os fatores relacionados ao gerenciamento que podem gerar ansiedade, reconhecidos pelas enfermeiras como situações inesperadas, estão centrados basicamente na falta de material, roupa e medicamentos, bem como na falta de pessoal, como pode ser verificado na Figura 2.

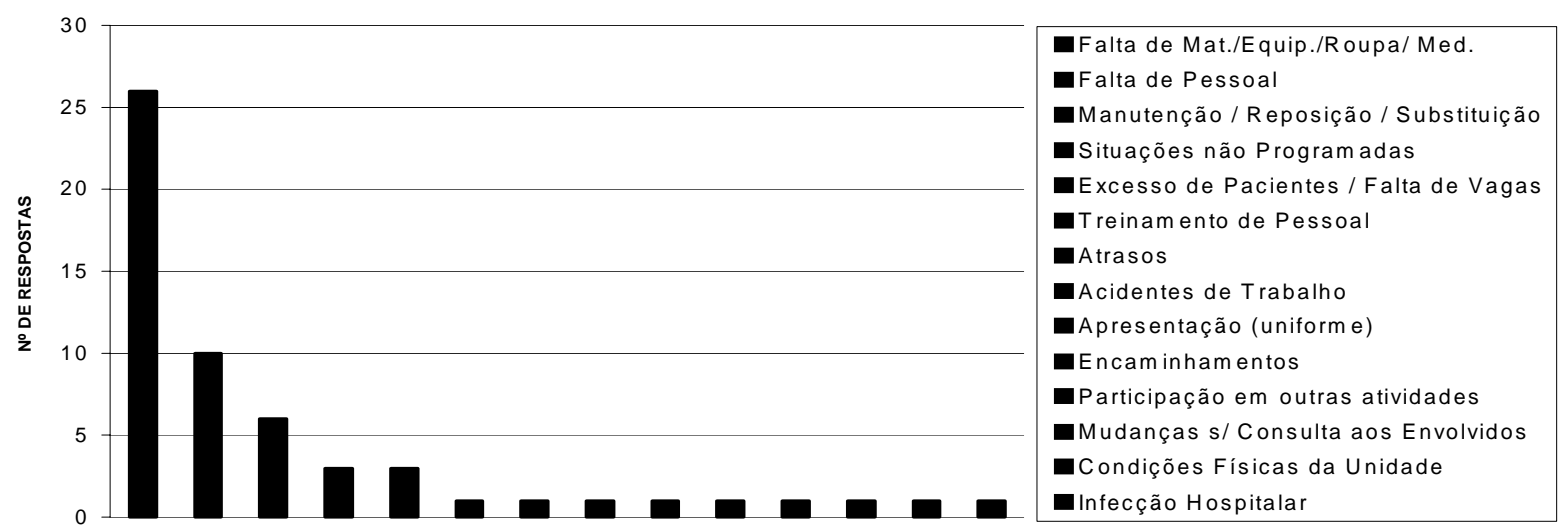

SITUAÇÕES CITADAS $(n=14)$

Figura 2 - Situações inesperadas $(n=14)$ que levam à ansiedade, relacionadas ao gerenciamento da unidade, citadas entre 54 enfermeiras do Hospital São Paulo. São Paulo, 1999

Situações inesperadas geradoras de ansiedade referentes ao relacionamento interpessoal

$\mathrm{Na}$ Figura 3 verificamos as situações inesperadas que mais levam à ansiedade, originadas pelo relacionamento interpessoal, tais como: a relação com a família do paciente, com a equipe de enfermagem e com o serviço de manutenção.
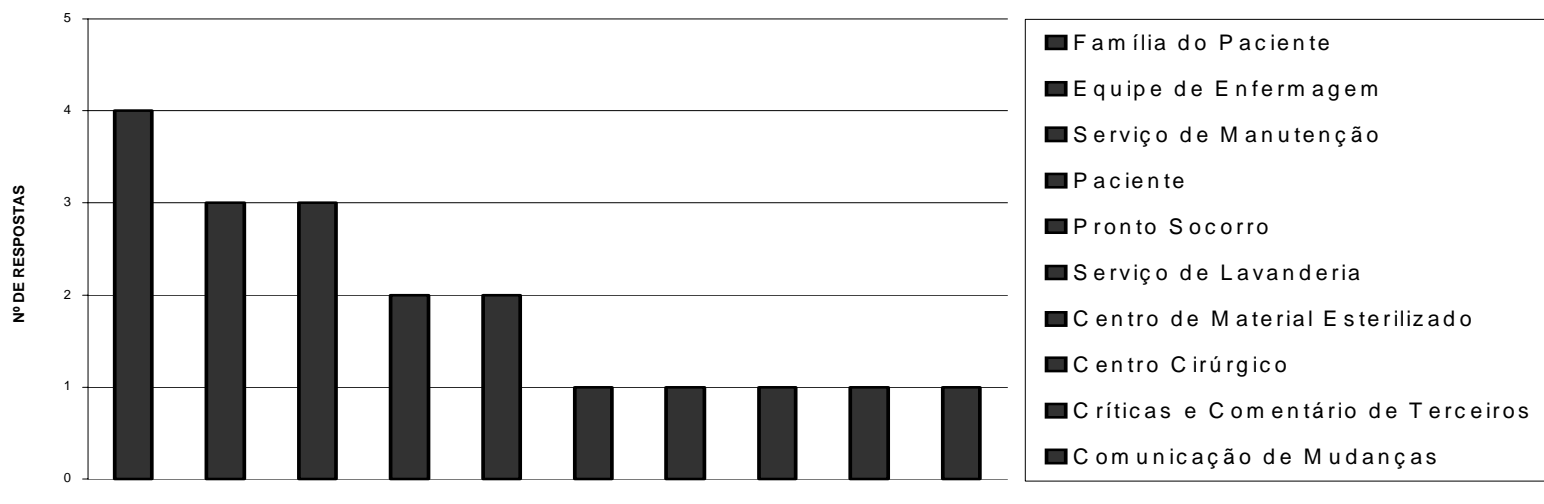

SITUAÇ Õ ES CIT ADAS $(n=10)$

Figura 3 - Situações inesperadas $(n=10)$ que levam à ansiedade, relacionadas ao relacionamento interpessoal, citadas entre 54 enfermeiras do Hospital São Paulo. São Paulo, 1999 
Situações do cotidiano geradoras de ansiedade

Mesmo as situações cotidianas podem ser geradoras de tensão e, portanto, de ansiedade.

Ao serem questionadas quanto à autopercepção da ansiedade nestas situações, as enfermeiras responderam quais, dentre elas, provocam o aumento da ansiedade e também determinaram o nível da mesma.

Situações do cotidiano geradoras de ansiedade relacionadas à assistência de enfermagem ao paciente

As enfermeiras listaram os procedimentos assistenciais que consideram geradores de ansiedade, que estão apresentados na Figura 4. Destacaram as atividades relacionadas à Sistematização da Assistência de Enfermagem e os procedimentos de alta complexidade. É compreensível que os procedimentos de alta complexidade sejam considerados ansiogênicos. A avaliação, entretanto, com relação à Sistematização da Assistência de Enfermagem é surpreendente, pois esta é uma atividade que deveria ser inerente ao dia a dia da enfermeira, e, portanto, não deveria ser geradora de ansiedade, o que merece ser observado mais atentamente para reconhecer o que motivou essa pontuação. É possível que essa resposta esteja relacionada à falta de conhecimento e experiência prática para o desenvolvimento da atividade ou mesmo que a Instituição possa estar exigindo novos conhecimentos.

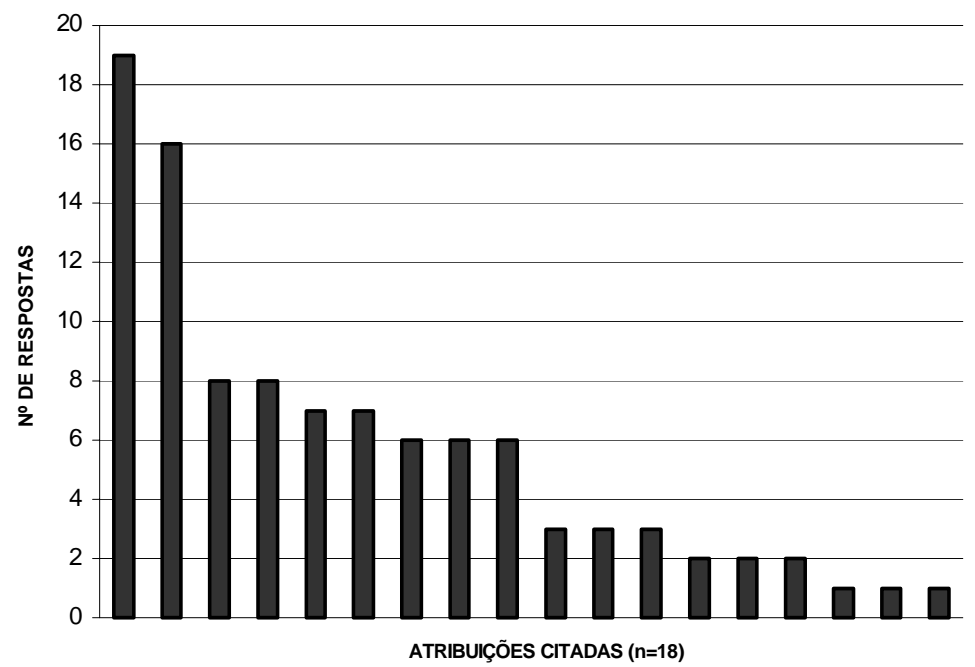

\begin{tabular}{|c|}
\hline 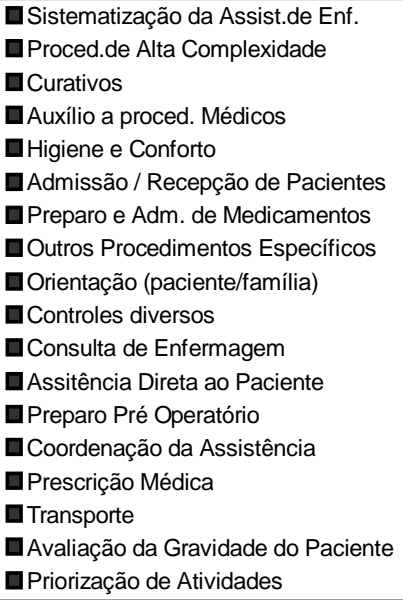 \\
\hline
\end{tabular}

Figura 4 - Atribuições cotidianas $(n=18)$ que elevam a ansiedade, relacionadas à assistência de enfermagem, citadas entre 54 enfermeiras do Hospital São Paulo. São Paulo, 1999

Situações do cotidiano geradoras de ansiedade relacionadas ao gerenciamento da unidade

Dentre os tópicos citados como geradores de ansiedade relacionados ao gerenciamento da unidade no dia-a-dia, destacaram-se o controle e distribuição de materiais e a confecção da escala de serviço. É provável que a ansiedade destacada nessas atividades esteja relacionada às situações inesperadas apontadas anteriormente, como a falta de suprimentos e de pessoal.

Situações do cotidiano geradoras de ansiedade, relacionadas ao ensino

Considerando tratar-se de um hospital escola, o ensino está implícito nas funções a serem exercidas pelas enfermeiras e foi apontado por elas como gerador de ansiedade. Essa atividade refere-se à participação da enfermeira no ensino de auxiliares de enfermagem, técnicos de enfermagem, outras enfermeiras, residentes de enfermagem e residentes de medicina.

Avaliação dos níveis de ansiedade nas situações inesperadas e cotidianas indicadas pelas enfermeiras

As 54 enfermeiras indicaram, subjetivamente, a autopercepção do nível de ansiedade nas situações inesperadas e cotidianas. Cada uma delas classificou, segundo sua própria percepção, o nível de ansiedade.

Os níveis de ansiedade foram classificados em: ausente, baixo; moderado; alto e grave. Apresentamos, percentualmente, para cada classe de situação e para cada área de atuação, os respectivos níveis de ansiedade apontados pelas enfermeiras. 
Tabela 1 - Avaliação percentual, feita pelas 54 enfermeiras, quanto ao nível de ansiedade vivenciados nas situações inesperadas e cotidianas

\begin{tabular}{|c|c|c|c|c|c|c|c|}
\hline & Níveis de ansiedade (\%) & Ausente & B aixo & Moderado & Alto & Grave & $\begin{array}{c}\text { Não } \\
\text { Respondeu }\end{array}$ \\
\hline \multirow{4}{*}{ 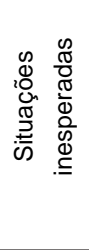 } & Assistência de enfermagem & 0 & 4 & 35 & 61 & 0 & 0 \\
\hline & Gerenciamento da unidade & 0 & 4 & 26 & 60 & 9 & 2 \\
\hline & Falta de equipamento/m aterial & 0 & 4 & 38 & 42 & 15 & 0 \\
\hline & Relacionamento interpessoal & 0 & 5 & 32 & 47 & 16 & 0 \\
\hline \multirow{3}{*}{ 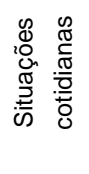 } & Assistência de enfermagem & 30 & 29 & 29 & 12 & 1 & 0 \\
\hline & Gerenciamento da unidade & 18 & 18 & 38 & 23 & 3 & 0 \\
\hline & Ensino & 20 & 40 & 26 & 3 & 0 & 11 \\
\hline
\end{tabular}

A Tabela 1 apresenta, em valores percentuais, a avaliação das 54 enfermeiras quanto aos níveis de ansiedade vivenciados nas situações inesperadas relacionadas à assistência de enfermagem ao paciente, ao gerenciamento da unidade (com destaque à falta de equipamentos e materiais) e ao relacionamento interpessoal.

O imprevisto é gerador de ansiedade, como se pode verificar a partir do percentual de respostas relacionadas às situações inesperadas, envolvendo a assistência ao paciente. Destacam-se aqui os níveis de ansiedade moderado e alto.

Nas situações inesperadas relacionadas ao gerenciamento, destaca-se o nível alto de ansiedade, compreendendo $60 \%$ das respostas. Essa situação causa preocupação, na medida em que o gerenciamento da unidade representa, para a enfermeira, uma atividade primordial, e o enfrentamento de situações imprevistas é freqüente. A falta de material, equipamento, roupa, medicamento, foram considerados como os fatores mais ansiogênicos dentre as situações relacionadas ao gerenciamento, destacando o nível alto, pois afetam diretamente a assistência ao paciente e comprometem o gerenciamento da unidade, podendo até mesmo interferir nas relações intersetoriais e interpessoais.

O relacionamento interpessoal foi também apontado pelas enfermeiras como fator ansiogênico, o que também é preocupante, pois permeia todas as atividades desenvolvidas por elas, na assistência, no gerenciamento e também no ensino. O percentual de respostas relativas a essas situações indica que o relacionamento interpessoal é desencadeador de ansiedade, em níveis moderado e alto.

A Tabela 1 apresenta, também, em valores percentuais, a avaliação das 54 enfermeiras quanto aos níveis de ansiedade experimentada nas situações cotidianas relacionadas à assistência de enfermagem ao paciente, ao gerenciamento da unidade e ao ensino.

As respostas relativas aos níveis de ansiedade nas situações cotidianas apontaram a assistência de enfermagem pontuada em uma freqüência similar nos níveis: ausente; baixo e moderado. O nível alto também está presente, ainda que em menor freqüência. $O$ fato de estarem presentes níveis de ansiedade, mesmo que predominantemente baixos, em atividades cotidianas, sugere uma provável interferência de característica da população que, em sua maioria, é recém formada e com pouco tempo na unidade de atuação. Assim, uma situação considerada cotidiana pode ser nova para a respondente que está experienciando inicialmente. Outra hipótese é que as enfermeiras podem estar atuando no cotidiano com certos níveis de ansiedade, que lhes causam desconforto emocional constante ou, até mesmo, impulsionando-as a novas reações.

Alguns autores questionam até que ponto podese considerar que a ansiedade é patológica e onde estão aumentados os seus níveis ${ }^{(10-11)}$. Sabemos que a ansiedade existencial é inerente à vivência do homem, especialmente em uma sociedade altamente ansiogênica. $O$ trabalho da enfermeira parece trazer, no cotidiano, segundo os dados desta pesquisa, carga de desconforto emocional. Aparentemente, segundo suas próprias avaliações, elas se mantêm continuamente em estado de tensão, classificado como moderado e alto.

Estratégias de manejo da ansiedade

No momento do aumento do nível de ansiedade

O fato de a pessoa identificar subjetivamente a ansiedade e classificá-la em um determinado nível, 
pressupõe que esteja usando estratégias de controle. Os sujeitos listaram, com suas próprias palavras, os mecanismos utilizados para diminuir a ansiedade no momento em que percebem aumentar o seu nível. A Figura
5 mostra esses dados, que estão apresentados em ordem decrescente de escolha: desabafar, chorar, estourar, dar uma volta, fingir não ligar, emburrar, não fazer nada, comer, ir à capela, fumar, entre outras.
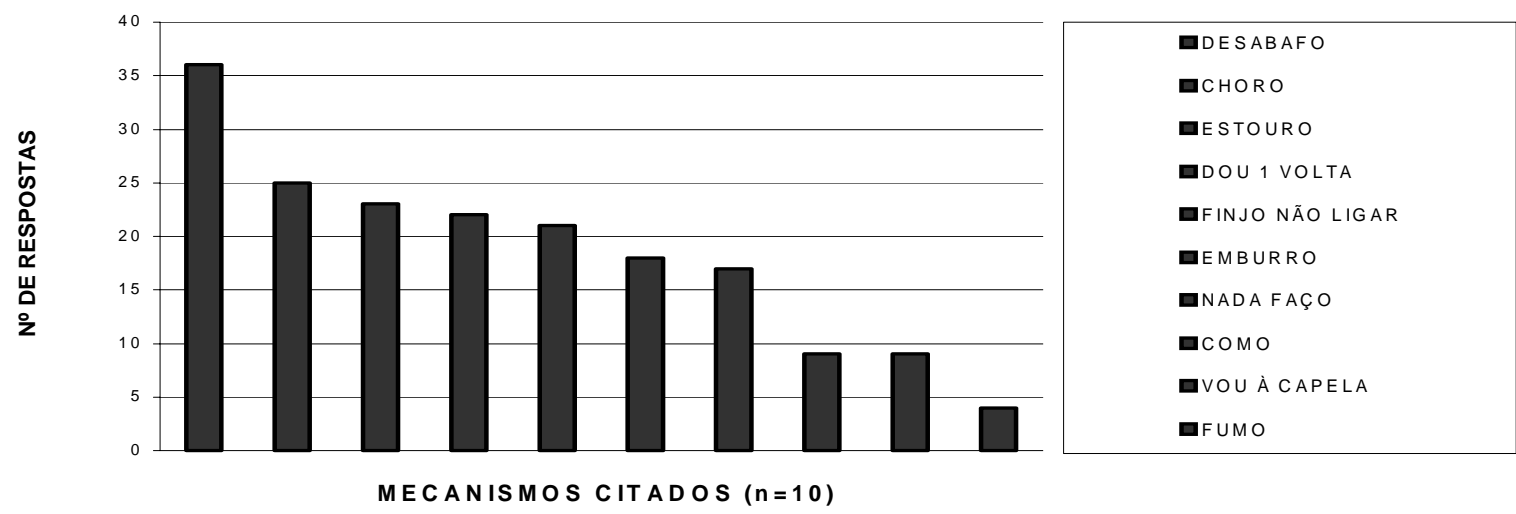

Figura 5 - Mecanismos ( $n=10)$ utilizados para diminuir o nível de ansiedade (na hora do ocorrido), citados entre 54 enfermeiras do Hospital São Paulo. São Paulo, 1999

No cotidiano

As enfermeiras listaram, também, as estratégias que utilizam para minimizar a ansiedade no seu cotidiano. As respostas apontadas seguem uma ordem decrescente: ouvir música, ver tv, tomar ducha, rezar, fazer compras, sair com amigos, desabafar, viajar, brincar com crianças, ir ao cinema, estudar, cantar, tomar chope, comer chocolate, praticar esporte, limpar a casa, arrumar gavetas, brincar com animais, fazer comidas, paquerar, cuidar de plantas, fazer sexo, ler, ir ao cabeleireiro e fumar.

\section{CONSIDERAÇÕES FINAIS}

Os objetivos deste estudo foram identificar situações, na atuação da enfermeira, consideradas como fontes geradoras de ansiedade e conhecer as estratégias conscientes que está usando para diminuir tais níveis de ansiedade, dependendo da situação vivenciada. Observando os dados, pode-se verificar que a ansiedade é apontada em níveis baixo, moderado, alto e até grave.

É conhecido que, nas profissões da área da saúde, a ansiedade tende a ser comum, visto que os profissionais lidam com o sofrimento humano, a morte, que são situações altamente ansiogênicas. A ansiedade da morte é a mais básica, mais universal e inexplicável para a pessoa. Todas as tentativas de negá-la são inúteis, até quando ela está sendo negada com argumentos em favor da imortalidade da alma. Mesmo assim, não convence existencialmente, pois o limite corporal é concreto e algo irá morrer, mesmo que os sujeitos desta pesquisa não tenham listado o lidar com o sofrimento ou a morte como gerador de ansiedade ou desconforto não podemos negá$\operatorname{los}^{(12)}$. Estes são fenômenos que nos ajudam a compreender que a enfermeira lida com altos níveis de ansiedade, o que é também comprovado por alguns autores $^{(5-6)}$.

Os dados resultantes desta pesquisa sugerem vários encaminhamentos no sentido de estudos futuros. Seria interessante verificar a relação da natureza do trabalho da enfermeira com o desenvolvimento tecnológico da medicina, que poderia ser gerador de ansiedade, por exigir que a enfermeira tenha contato contínuo com técnicas e procedimentos sempre renovados e, com isso, possa ter dificuldade em garantir a qualidade de sua produção.

Da amostra analisada, 16 enfermeiras (29,6\%) realizam dupla jornada de trabalho. Consideramos esse dado importante, pois a sobrecarga de trabalho pode significar um fator desencadeante de ansiedade entre esses profissionais, visto que as enfermeiras são, em maioria quase absoluta, do sexo feminino. Essas enfermeiras podem ter, além da dupla jornada de trabalho no hospital, uma outra jornada: cuidando da casa e sendo responsáveis pela educação dos filhos. Esse fato levanos a sugerir uma futura análise sobre a repercussão das duplas jornadas de trabalho na vida desses profissionais e verificar se são percebidas como desencadeantes de ansiedade entre eles.

Estes são apenas alguns exemplos dos fatores 
apontados pelos sujeitos como geradores de ansiedade.

Ao apresentarem níveis perceptíveis de ansiedade, pressupomos que devem estar usando táticas e estratégia de tentativa de controle e de superação da ansiedade. Nesse sentido, obtivemos respostas no mínimo intrigantes. As estratégias que estão sendo usadas pelos sujeitos deste estudo são relativamente saudáveis, ao contrário do que é apontado por alguns autores ${ }^{(4)}$. Estratégias como: ouvir música, dar uma volta, desabafar, são mecanismos que podem estar ajudando, de alguma forma, a enfermeira a manter-se mais saudável no trabalho e contribuindo para que a manutenção deste trabalho também seja mais adequada. No entanto, outros estudos quantitativos $\mathrm{e}$ qualitativos deverão ser feitos, para aprofundar e conhecer melhor a questão da ansiedade neste grupo de enfermeiras. Nossa intenção não é propor tratamento, mas reconhecer a questão, verificar como ela está sendo lidada no dia a dia e, futuramente, propor algumas alternativas que possam colaborar para melhorar a qualidade de vida das enfermeiras.

\section{REFERÊNCIAS BIBLIOGRÁFICAS}

1. Ey M, Bernard P, Brisset C. Manual de Psiquiatria. São Paulo (SP): Mansson do Brasil; 1988.

2. Silva ES. Os vínculos entre condições de trabalho e saúde mental. Psicol Cien Prof 1995 junho; 2(3):13-7.

3. Fadiman J, Frager R. Teorias da personalidade. São Paulo (SP): Harper \& Row do Brasil; 1982.

4. Menzies I. The functioning of organizations as social systems of defense against anxiety. Londres: Tavistock Institute of Human Relation; 1975.

5. Takahashi EIU. As fontes de estresse emocional que afetam a enfermeira na assistência à criança grave. Rev Esc Enfermagem USP 1985 agosto;19(1):5-20.

6. Queiroz JP Filho. Reflexões sobre a equipe psiquiátrica. Sinonímia: Equipe de Saúde mental, equipe psiquiátrica multidisciplinar, equipes de de profissionais de Saúde mental. J Bras Psiquiatr 1993 out; 42(9):469-81.

7. Sawaia BB. Dimensão ético-afetiva do adoecer da classe trabalhadora. In: Lane STM, Sawaia BB, organizadores. Novas veredas da psicologia social. São Paulo (SP): BrasilienseEDUC; 1995. p.157-68.

8. Lambert AA, Oliveira CM. As vivências ansiosas nos trabalhadores em saúde mental: estudo qualitativocomparativo como os funcionários de hospitais gerais e empresas de variadas atividades. Rev Bras Saúde Ocupacional 1996 fev; 2(4):93-104.

9. Caplan G. Princípios de Psiquiatria preventiva. Rio de Janeiro (RJ): Zahar; 1982.

10. Zung WWK. How normal are anxiety and depression? Arch Gen Psychiatr 1982 junho; 1(3):173-8.

11. Bernik V, Bernik M. Ansiedade: uma revisão dos tratamentos mais atualizados existentes. Rev Bras Med Psiquiatr 1991 out; 1(2):14-20.

12. Tillich P. A coragem de ser. $3^{\underline{a}}$ ed. Rio de Janeiro (RJ): Paz e Terra; 1986. 